Research Paper

\title{
The Efficacy, Safety and Cost-Effectiveness of Intra-Operative Cell Salvage in High-Bleeding-Risk Cardiac Surgery with Cardiopulmonary Bypass: A Prospective Randomized and Controlled Trial
}

\author{
Yihong $X_{i e^{1}}$, Sheliang Shen ${ }^{2}{ }^{\bowtie}$, Jun Zhang33, Wenyuan Wang${ }^{2}$, Jiayin Zheng ${ }^{4}$ \\ 1. Department of Cardiothoracic surgery, Zhejiang Provincial People's Hospital, Hangzhou, Zhejiang, China. \\ 2. Department of Anesthesiology, Zhejiang Provincial People's Hospital, Hangzhou, Zhejiang, China. \\ 3. Department of Orthopedics, Zhejiang Provincial People's Hospital, Hangzhou, Zhejiang, China. \\ 4. Department of Probability and Statistics, School of Mathematical Sciences, Beijing University, Beijing, China.
}

$\triangle$ Corresponding author: Sheliang Shen, MD, Department of Anesthesiology, Zhejiang Provincial People's Hospital, Shangtang Road 158, Hangzhou, Zhejiang, 310014, China. Email: hz-ssl@163.com. Tel: +86-13857194168

(c) 2015 Ivyspring International Publisher. Reproduction is permitted for personal, noncommercial use, provided that the article is in whole, unmodified, and properly cited. See http://ivyspring.com/terms for terms and conditions.

Received: 2014.12.03; Accepted: 2015.03.16; Published: 2015.04.01

\begin{abstract}
Objective: Intra-operative cell salvage (CS) was reported to be ineffective, safe and not cost-effective in low-bleeding-risk cardiac surgery with cardiopulmonary bypass (CPB), but studies in high-bleeding-risk cardiac surgery are limited. The objective of this study is to evaluate the efficacy, safety and cost-effectiveness of intra-operative CS in high-bleeding-risk cardiac surgery with CPB.

Methods: One hundred and fifty patients were randomly assigned to either with intra-operative CS group (Group CS) or without intra-operative CS group (Group C). Study endpoints were defined as perioperative allogeneic red blood cell (RBC) transfusion, perioperative impairment of blood coagulative function, postoperative adverse events and costs of transfusion-related.

Results: Both the proportion and quantity of perioperative allogeneic RBC transfusion were significantly lower in Group CS than that in Group C ( $p=0.0002,<0.0001$, respectively). The incidence of residual heparin and total impairment of blood coagulative function in the 24 hours after surgery, the incidence of postoperative excessive bleeding, were significantly higher in Group CS than that in Group $C(p=0.018,0.042,0.034$, respectively). Cost of both allogeneic RBC transfusion and total allogeneic blood transfusion were significantly lower in Group CS than that in Group $C(p<0.001,=0.002$, respectively). Cost of total blood transfusion was significantly higher in Group CS than that in Group C ( $p=0.001)$.

Conclusion: Intra-operative CS in high-bleeding-risk cardiac surgery with CPB is effective, generally safe, and cost-effective in developed countries but not in China.
\end{abstract}

Key words: cardiac surgery, risk grade, blood transfusion, autologous, operative blood salvage

\section{Introduction}

Patients undergoing cardiac surgery with cardiopulmonary bypass (CPB) are often exposed to acute anemia as the red blood cell (RBC) were damaged and the circulatory system was primed of large volumes of fluid [1]. As we have known, anemia is closely related with postoperative adverse events, such as stroke and kidney injury. Thus, it is quite important to treat anemia in time during periopera- 
tive period [1, 2]. The most simple and effective approach in the treatment of anemia is allogeneic RBC transfusion, but it still has many disadvantages, including the spread of infectious diseases like AIDS, suppressing immunoreaction, increasing postoperative adverse events and medical costs, aggravating blood shortage $[3,4]$.

In order to reduce the incidence of adverse events resulting from allogeneic RBC transfusion and to cope with increasing blood shortage and medical costs, cell salvage (CS) was applied in cardiac surgery with $\mathrm{CPB}$ and recommended by blood conservation guidelines [5, 6]. However, recently many studies indicated that CS was ineffective and not cost-effective in low-bleeding-risk cardiac surgery, although it was safe [3, 5-9].

High-bleeding-risk cardiac surgery with $\mathrm{CPB}$ refers to those surgeries with high risk of bleeding brought by the patient's poor physical condition and the surgery's long time and complexity $[4,5,8,10,11]$. Until now, few data has existed to evaluate intra-operative CS in high-bleeding-risk cardiac surgery [12]. The aim of our prospective, randomized, controlled clinical trials was to evaluate the efficacy, safety and cost-effectiveness of intra-operative CS in this kind of surgery. The endpoint of efficacy was proportion and quantity of perioperative allogeneic RBC transfusion; the endpoint of safety was the incidence of perioperative impairment of blood coagulative function and the incidence of postoperative adverse events; the endpoint of cost-effectiveness was costs of transfusion- related.

\section{Methods}

\section{Patient enrollment}

The study was approved by the Ethics Committee of the Zhejiang Provincial People's Hospital (RCT ID: ChiCTR-TRC-13003209). Patients were enrolled in after they provided written informed consent. And there were 3 inclusion criteria that should be satisfied at the same time: firstly, patients were scheduled for cardiac surgery with $\mathrm{CPB}$; secondly, surgery was combined aortic valve replacement and mitral valve replacement, or Bentall (aortic valve replacement and ascending aorta and aortic root replacement), or reoperation (single or multiple valve replacement); thirdly, at least two of the following conditions are satisfied: (1)age $>70$ years; (2)body surface area $(\mathrm{BSA})<1.6 \mathrm{~m}^{2}$; (3)renal dysfunction (creatinine $>15 \mathrm{mg}$ $\mathrm{L}^{-1}$ ); (4)liver insufficiency (Child -Pugh B or C); (5)coagulation disorders (thromboelastography, TEG, $R$ value before surgery $>10 \mathrm{~min}$ ); (6) hemoglobin(HB) levels < $130 \mathrm{~g} \mathrm{~L}^{-1}$ in males or $<120 \mathrm{~g} \mathrm{~L}^{-1}$ in females; (7) Platelets (PLT) count $<50 \times 10^{9} \mathrm{~L}^{-1}$; 8)intake of as- pirin 3 days before surgery or clopidogrel 7 days before surgery $[3,5,1011]$. One hundred and fifty eligible patients were randomly assigned into two groups according to a randomization list: cell salvage group (Group CS) and control group (Group C). Patients in Group CS were treated with intra-operative CS while those in Group C without.

\section{CPB}

After anesthesia induction Tranexamic Acid (AMCHA, $30 \mathrm{mg} \mathrm{kg}^{-1}$ ) was infused into all patients [13]. Anticoagulation was achieved with heparin to maintain an activated clotting time (ACT) over 480 seconds. After separation from $\mathrm{CPB}$, heparin was neutralized with protamine to a target- ACT of within $90-110 \%$ of base value.

\section{Autologous blood transfusion}

In Group CS, shed blood from wound and mediastina were sucked into the cell saver reservoir (Haemonetics, USA, volume of disposable centrifuge bowl is $125 \mathrm{~mL}$ ) after anticoagulated by heparin during the period of non-heparinization. At the end of $\mathrm{CPB}$, residual blood in the $\mathrm{CPB}$ circuit was sucked into the reservoir directly. After filtrated, centrifugated, washed and concentrated, the recovered blood became autologous blood (autologous RBC) [14, 15], and was then transfused back to the patients immediately. All autologous RBC was transfused back before the end of surgery. In Group C, shed blood from wound and mediastina during the period of non-heparinization and residual blood were sucked into suction apparatus and were discarded. Patients' bleeding during the period of heparinization both in groups CS and Group C were sucked into the CPB circuit.

\section{Perioperative blood transfusion}

Perioperation was the period from the before surgery to $24 \mathrm{~h}$ after surgery. From $5 \mathrm{~min}$ after heparin was neutralized during surgery to $24 \mathrm{~h}$ after surgery, if the hemoglobin (HB) was lower than $80 \mathrm{~g} \mathrm{~L}^{-1}$, patients in Group $C$ were transfused with allogeneic RBC while patients in Group CS were transfused with autologous RBC first. If the $\mathrm{HB}$ level is still lower than $80 \mathrm{~g} \mathrm{~L}^{-1}$ after all the autologous RBC was used up, allogeneic RBC would be transfused then. Postoperative excessive bleeding patients were treated according to the protocol in Figure $1[8,16]$.

\section{Study variables}

Basal and operative characteristics: age, gender, BSA, the type of surgery, complications, CPB time, surgical time, tracheal intubation time, ICU time, length of hospital stay, the volume of residual blood in $\mathrm{CPB}$ circuit, the volume of intraoperative blood 
loss, the volume of mediastina tube drainage (MTD) 6 $\mathrm{h}$ and $24 \mathrm{~h}$ after surgery, intraoperative dosage of heparin and protamine.

Perioperative blood transfusion: the volume of autologous RBC transfusion in Group CS, the proportion and quantity of allogeneic blood transfusion [RBC, PLT and fresh-frozen plasma (FFP)] in two groups.

Perioperative hematological and Thromboelastography (TEG) parameters: vein blood were tested for hematological and TEG (Haemonetics, USA) parameters at the following four time points and postoperative excessive bleeding occurred in the 24 hours after surgery (post-op): at the time of after anesthesia induction and before surgery $\left(\mathrm{T}_{1}\right), 5 \mathrm{~min}$ after heparin was neutralized during surgery $\left(\mathrm{T}_{2}\right)$, at the end of surgery $\left(\mathrm{T}_{3}\right)$ and $24 \mathrm{~h}$ after surgery $\left(\mathrm{T}_{4}\right)$. Hematological parameters included RBC, HB, PLT and FIB; TEG pa- rameters included $\mathrm{R}$ value (R-TEG and $\mathrm{R}$-h-TEG), MA and LY 30 [15].

Perioperative impairment of blood coagulative function: impairment of blood coagulative function was diagnosed according to the seventh and eighth lines in Figure 1, 5 types of impairment included residual heparin, hypocoagulability for low PLT, hypocoagulability for low FIB, hypocoagulability for low coagulation factors, hyperfibrinolytic $[16,17]$.

Postoperative adverse events: excessive bleeding, resternotomy, cardiovascular failure, severe arrhythmias, myocardial infarction, infection, renal failure, respiratory failure, epileptic syndrome, cognitive decline and death.

Costs of transfusion-related: cost of autologous blood transfusion, cost of allogeneic blood transfusion, cost of total blood transfusion and cost of total hospital.

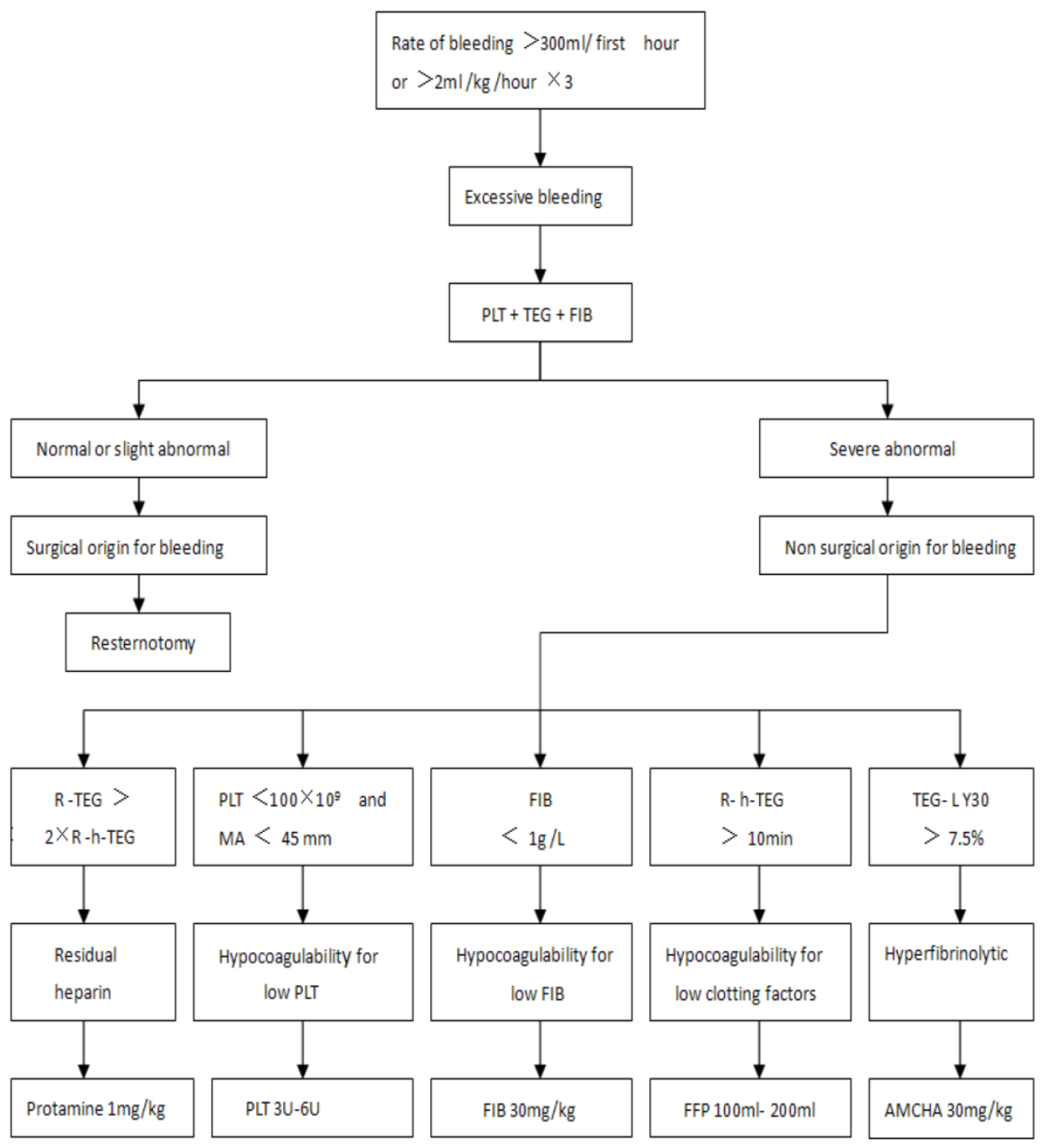

Figure 1 The processing protocol of postoperative excessive bleeding. Once excessive bleeding was diagnosed, patients received treatment based on the results of the tests in the PLT, TEG and FIB. First hour=in the first hour after surgery, hour $\times 3=$ for 3 consecutive hours. TEG=celite-activated TEG, h-TEG= heparinase-modified celite-activated TEG. $R=$ reaction time, $R-T E G=R$ value in $T E G, R-h-T E G=R$ value in $h-T E G$. $M A=$ maximum amplitude, $L Y 30=l y$ sis index at 30 min. $\mathrm{PLT}=$ Platelets, $\mathrm{FFP}=$ fresh-frozen plasma, $\mathrm{FIB}=$ fibrinogen, $\mathrm{AMCHA}=$ Tranexamic Acid. 


\section{Statistical analysis}

The quantity of perioperative allogeneic RBC transfusion is an important scale of the efficacy. In our previous preliminary study, the range and the median of allogeneic RBC transfusion were 2 to $12 \mathrm{U}$ and $4 \mathrm{U}$, respectively. In most observations, $99 \%$ of the ranges are within $\pm 3 \mathrm{SD}$ (standard deviation), so $1 / 6 \times$ range $=1 \mathrm{SD}=1.67 \mathrm{U}$. To achieve a $25 \%(1 \mathrm{U})$ reduction of allogeneic RBC transfusion, based on a two-sided significance level of $5 \%$, we calculated that a sample size of 96 patients (48 in each group) would provide $90 \%$ power to detect statistical difference [18].

The data are presented as mean (SD) for continuous parametric values, or as numbers with percentage for categorical data. For continuous data, the two-sample two-sided Student's t-test and the Wilcoxon Rank-Sum two-sample two-sided test were used. For categorical data, the Chi-square-test and Fisher's exact-test were used. Considering some variables may influence relevant clinical outcomes potentially, the logistic regression model was used to verify the relationship of CS with 7 perioperative impairment of blood coagulative function and postoperative adverse events, including residual heparin, hypocoagulability for low PLT, hypocoagulability for low FIB, hypocoagulability for low clotting factors, excessive bleeding, myocardial infarction and cognitive decline. Odds ratios (ORs) resulting from logistic regression analysis were used to estimate relative risk (RR) ratios. Data analysis were performed using SAS statistical software (version 9.1; SAS Institute Inc., Cary, NC, USA). $P$ values below 0.05 were accepted as significant.

\section{Results}

Patients' progress is summarized in Figure 2. The Basal and operative characteristics were almost identical between the two groups (Table 1).

The volume of autologous RBC transfusion in Group CS was $817.7 \pm 67.8 \mathrm{~mL}(\approx 4.09 \mathrm{U})$. Both the proportion and quantity of perioperative allogeneic RBC transfusion were significantly lower in Group CS than that in Group C (Table 2).

There were no significantly difference of hematological and TEG parameters at different time point from $T_{1}$ to $T_{4}$ between two groups $(p>0.05)$. Both the incidence of residual heparin and the incidence of total impairment of blood coagulative function at $T_{3}$ and in the 24 hours after surgery were significantly higher in Group CS than that in Group C (Figure 3). The incidence of postoperative excessive bleeding was significantly higher in Group CS than that in Group C $(p=0.034)$. There was no significantly difference of the incidence of total postoperative adverse event between two groups $(p=0.602)$. CS was associated with an increase in the RR for perioperative residual heparin and postoperative excessive bleeding ( $p=0.032$, 0.048 , respectively).

Both the cost of allogeneic RBC transfusion and the cost of total allogeneic blood transfusion were significantly lower in Group CS than that in Group C. The cost of total blood transfusion was significantly higher in Group CS than that in Group C (Table 3). Table 4 analysed the cost-effectiveness of CS in different studies $[8,12,19]$. In our study the mean of autologous RBC transfusion was $4.09 \mathrm{U}, \mathrm{CS}$ was cost-effective according to the price of allogeneic RBC in developed countries but not cost-effective in terms of the price in China.

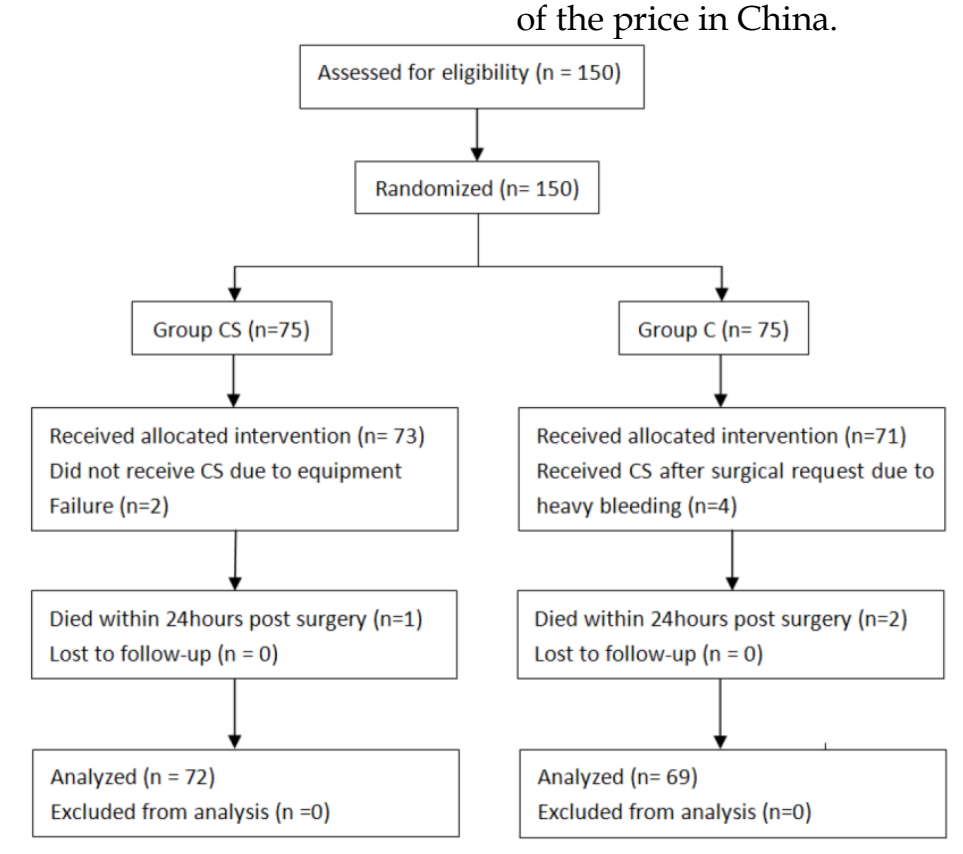

Figure 2 CONSORT diagram of flow of patients 


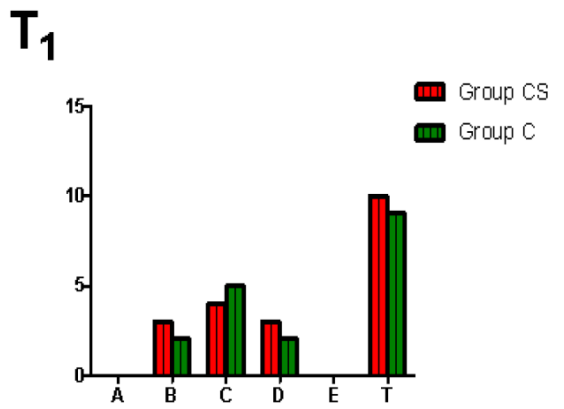

$\mathbf{T}_{2}$

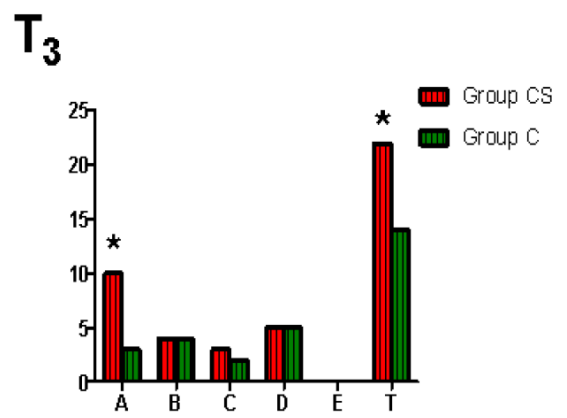

Post-op

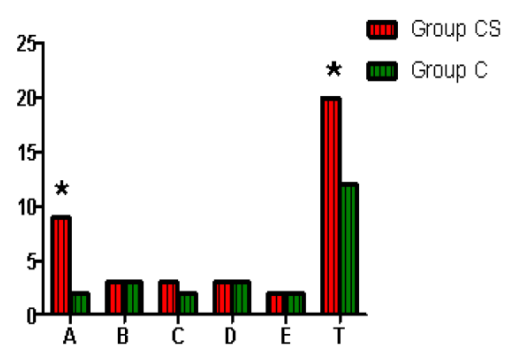

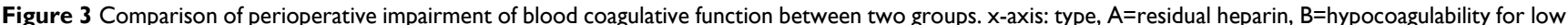
platelet, $C=$ hypocoagulability for low FIB, $D=$ hypocoagulability for low clotting factors, $E=$ hyperfibrinolysis, $T=$ total $(A+B+C+D+E) . y$-axis: cases. $T$, $=$ at the time of after anesthesia induction and before surgery, $T_{2}=5 \mathrm{~min}$ after heparin was neutralized with protamine during surgery, $T_{3}=$ at the end of surgery, post-op=in the 24 hours after surgery. ${ }^{*} p=0.025\left(\mathrm{~T}_{3}-\mathrm{A}\right), 0.037$ ( $\left.\mathrm{T}_{3}-\mathrm{T}\right), 0.018$ (post-op-A), 0.042 (post-op-T), respectively.

Table 1: Patients' basal and operative characteristics

\begin{tabular}{|c|c|c|c|}
\hline Variable & $\begin{array}{l}\text { Group CS } \\
(n=72)\end{array}$ & $\begin{array}{l}\text { Group C } \\
(n=69)\end{array}$ & $P$ value \\
\hline Age(years) & $51.7(15.6)$ & $53.1(15.1)$ & 0.548 \\
\hline$>70$ years & $17(23.6)$ & $16(23.2)$ & 0.682 \\
\hline Male & $35(48.6)$ & $29(42.0)$ & 0.778 \\
\hline BSA & $1.75(0.13)$ & $1.72(0.15)$ & 0.932 \\
\hline$<1.6 \mathrm{~m}^{2}$ & $7(9.7)$ & $7(10.1)$ & 0.985 \\
\hline Surgery type & & & 0.938 \\
\hline multiple valve & $47(65.3)$ & $46(66.7)$ & \\
\hline Bentall & $10(13.9)$ & $8(11.6)$ & \\
\hline reoperations & $15(20.8)$ & $15(21.7)$ & \\
\hline \multicolumn{4}{|l|}{ Complication } \\
\hline renal dysfunction & $26(36.1)$ & $24(34.8)$ & 0.923 \\
\hline liver insufficiency & $12(16.7)$ & $13(18.8)$ & 0.537 \\
\hline coagulation disorders & $20(27.8)$ & $18(26.1)$ & 0.821 \\
\hline HB levels lower & $30(41.7)$ & $30(43.5)$ & 0.687 \\
\hline PLT abnormal & $20(27.8)$ & $21(30.4)$ & 0.752 \\
\hline intake of aspirin or clopidogrel & $18(25.0)$ & $15(21.7)$ & 0.702 \\
\hline CPB time $(\mathrm{min})$ & 140.2(32.7) & $124.5(28.9)$ & 0.311 \\
\hline Surgical time (min) & $280.4(31.7)$ & $258.7(37.4)$ & 0.204 \\
\hline Tracheal intubation time (hour) & $12.5(11.2)$ & $13.4(4.7)$ & 0.274 \\
\hline ICU stay (hour) & $20.5(5.7)$ & $21.8(4.7)$ & 0.253 \\
\hline Hospital stay (day) & 23.1(7.8) & $25.1(9.1)$ & 0.263 \\
\hline Residual blood in CPB circuit & $870.3(47.5)$ & $858.7(80.2)$ & 0.372 \\
\hline Intraoperative blood loss (ml) & $1425.6(162.4)$ & $1347.5(179.8)$ & 0.105 \\
\hline MTD (ml), in 6hour & $381.5(158.4)$ & $294.2(165.7)$ & 0.287 \\
\hline in 24 hour & 631.4.(287.6) & $559.8(193.4)$ & 0.067 \\
\hline Intraoperative heparin dose (mg) & $240.5(47.7)$ & $241.0(48.2)$ & 0.791 \\
\hline Intraoperative protamine dose(mg) & $422.2(90.6)$ & $410.2(94.5)$ & 0.507 \\
\hline
\end{tabular}

Data are presented as mean (SD) or number (percentage). BSA= body surface area.

MTD = mediastinal tube drainage, patients with resternotomy were not calculated.
Table 2: Perioperation allogeneic blood transfusion

\begin{tabular}{lclll}
\hline Variable & & $\begin{array}{l}\text { Group CS } \\
(n=72)\end{array}$ & $\begin{array}{l}\text { Group C } \\
(n=69)\end{array}$ & $P$ value \\
\hline RBC & proportion & $27(37.5)$ & $52(75.4)$ & 0.0002 \\
& quantity (U) & $2.01(2.75)$ & $5.39(3.28)$ & $<0.0001$ \\
FFP & & & \\
& quantity (ml) & $113.9(202.7)$ & $133.3(220.6)$ & 0.725 \\
& proportion & $14(19.4)$. & $14(20.3)$ & 0.909 \\
PLT & quantity (U) & $1.97(3.57)$ & $1.91(3.42)$ & 0.879 \\
& proportion & $16(22.2)$ & $13(18.8)$ & 0.627 \\
\hline
\end{tabular}

Data are presented as mean (SD) or number (percentage).

Table 3: Costs of transfusion- related

\begin{tabular}{clll}
\hline Variable & $\begin{array}{l}\text { Group CS } \\
(n=72)\end{array}$ & $\begin{array}{l}\text { Group C } \\
(n=69)\end{array}$ & $P$ value \\
\hline $\begin{array}{c}\text { Autologous blood transfusion } \\
\text { Allogeneic blood transfusion }\end{array}$ & 243.9 & 0 & \\
RBC & & & \\
FFP & $45.7(54.3)$ & $122.7(65.6)$ & $<0.001$ \\
PLT & $14.8(37.5)$ & $17.3(32.4)$ & 0.825 \\
Total (RBC+ FFP+ PLT) & $56.1(51.5)$ & $54.4(42.7)$ & 0.978 \\
Total blood transfusion & $116.6(140.8)$ & $194.4(152.4)$ & 0.002 \\
Total hospital & $360.5(140.8)$ & $194.4(152.4)$ & 0.001 \\
\hline
\end{tabular}

Data are presented as mean (SD) in United States dollars. exchange rate :\$1= $¥ 6.15$. Autologous blood transfusion $=$ price of annual equivalent of the cell saver machine (\$31.8) + price of disposable bowl and other consumable materials (\$212.1). Allogeneic blood transfusion = price of allogeneic blood product + price of the service charge of skilled staff. Allogeneic blood product was obtained from the Blood Service of Zhejiang Province, price of RBC, FFP and PLT were $\$ 17.88 / \mathrm{U}$, $\$ 0.08 / \mathrm{ml}$ and $\$ 23.58 / \mathrm{U}$, respectively; price of service of RBC, FFP and PLT were $\$ 4.88 / \mathrm{U}, \$ 0.05 / \mathrm{ml}$ and $\$ 4.88 / \mathrm{U}$, respectively.

Total blood transfusion $=$ cost of autologous blood transfusion + cost of allogeneic blood transfusion. 
Table 4: Cost-effectiveness of CS in different studies

\begin{tabular}{|c|c|c|c|c|}
\hline Study & Klein & Weltert & Ours & Shander and Weltert \\
\hline Country & Britain & Italy & China & $\begin{array}{l}\text { Developed countries } \\
\text { (Italy, Britain, America, } \\
\text { Switzerland, Austria) }\end{array}$ \\
\hline Year & 2007 & 2012 & 2014 & 2012(Italy), 2007(others) \\
\hline Cases & 94 & 537 & 72 & / \\
\hline Bleeding-risk of surgery & Low & $\begin{array}{l}\text { Low } \\
\text { and } \\
\text { high }\end{array}$ & High & High \\
\hline $\begin{array}{l}\text { Price of allogeneic RBC } \\
(\$ / U)^{A}\end{array}$ & 219 & 201 & 22.8 & 203 \\
\hline $\begin{array}{l}\text { Quantity of autologous } \\
\text { RBC transfusion (U) }\end{array}$ & / & 1.95 & 4.09 & 4.09 \\
\hline $\begin{array}{l}\text { Price of autologous blood } \\
\text { transfusion }(\$)^{\mathrm{C}}\end{array}$ & 153 & 258 & 243.9 & 258 \\
\hline Cost of reduced $(\$)^{\mathrm{D}}$ & -103 & 134 & -150.6 & 572.3 \\
\hline Cost-effectiveness & No & Yes & No & Yes \\
\hline
\end{tabular}

\section{Discussion}

Our present study shows that intra-operative CS in high-bleeding-risk cardiac surgery with CPB is effective, generally safe and cost-effective in developed countries but not cost-effective in China. To the best of our knowledge, this is the first prospective, randomized and controlled trial to evaluate intra-operative CS in this kind of surgery. Among 1.25 million patients undergoing cardiac surgery all over the world each year, a large proportion is with high-bleeding-risk [13]. Our study has a positive effect on this kind of surgery for reducing the requirement of the allogeneic RBC transfusion, decreasing the incidence of postoperative adverse events associated with anemia and allogeneic RBC transfusion, and reducing the medical costs in developed countries $[3$, $4]$.

In our study, intra-operative CS decreased the quantity and proportion of allogeneic RBC transfusion, which indicated that CS is effective in high-bleeding-risk cardiac surgery. The mechanism is that this kind of surgery has characteristics including higher risk of impairment of blood coagulation function, higher proportion of reoperation and longer time of $\mathrm{CPB}$, so that the volume of intraoperative blood loss is much larger than low-bleeding-risk cardiac surgery $[8,15]$.

TEG is particularly suitable for the diagnosis of impairment of blood coagulative function in cardiac surgery [20-22]. In our study it revealed that CS increased the incidence of perioperative residual heparin and total impairment of blood coagulative function. In addition, the incidence of postoperative excessive bleeding was higher in Group CS. These results indicated that intra-operative CS in high-bleeding-risk cardiac surgery impaired blood coagulative. The main mechanism is that the larger volume of intraoperative blood loss resulting in the larger volume of autologous blood transfusion, and the concentration of heparin in autologous blood was high while the platelet and coagulation factor was deficient. Another mechanism is that the long CPB time aggravates the hyperfibrinolysis [4, 9, 23]. However, we also found that CS did not increase the quantity and proportion of the allogeneic FFP and PLT transfusion, not increase the incidence of postoperative resternotomy and total adverse events. These results indicated that although CS could impair blood coagulation function to a certain degree, it was safe in general. The reason is that the impairment of blood coagulative function and postoperative excessive bleeding mainly result from the residual heparin which can be neutralized easily with protamine, while dilutional coagulopathy and hyperfibrinolysis also existed in Group C. The incidence of postoperative myocardial infarction and cognitive decline in Group CS did not decrease, which is inconsistent with George and colleagues' report [14, 15], and the reason may be our relatively small sample size.

There are few studies that have analyzed the cost-effectiveness of intra-operative CS in cardiac surgery $[8,12]$. Weltert and colleagues reported that it was cost-effective if either of the following two conditions are satisfied: partial patients were with high-bleeding-risk or the quantity of intraoperative blood loss was larger than $800 \mathrm{ml}[9,12,24]$, which is inconsistent with ours. In our study, all the patients were with high-bleeding-risk and the quantity of intraoperative blood loss was $1425.6 \mathrm{ml}$ but CS was still not cost-effective. It is the low price of allogeneic RBC in China that the reason is. Because the price in developed countries is 8.9 times as much as that in China (203/22.8), intra-operative CS in high-bleeding-risk cardiac surgery is cost-effective.

The primary limitation of our study was the evaluation standard of high-bleeding- risk cardiac surgery. Because there is no unified standard until now, the standard we employed may need some improvement. Another limitation was the relatively small sample size. Although it was sufficient for detecting the difference in quantity of allogeneic RBC transfusion between groups, a larger sample size is necessary to detect possible differences in safety.

In summary, our preliminary data support a proposal that intra-operative CS in high-risk-bleeding cardiac surgery with $\mathrm{CPB}$ can reduce the proportion and quantity of perioperative allergenic RBC transfusion without adding the incidence of total postoperative adverse event, while impair the blood coagulation function to a certain degree and increase the in- 
cidence of postoperative excessive bleeding. The cost-effectiveness of intra-operative CS in this kind of surgery mainly depends on the price of allogeneic RBC. Thus, intra-operative CS in this kind of surgery is effective, generally safe and cost-effective in developed countries but not cost-effective in China. Future studies should be performed to further evaluate the safety in a larger sample size.

\section{Acknowledgments}

Funding for the study was provided by the Natural Science Foundation of Zhejiang Province (LY12H08005). The authors are grateful to $\mathrm{Dr}$ Shuangfei Hu of the Department of Anesthesiology of Zhejiang Provincial People's Hospital and Dr Linhai $\mathrm{Xu}$ of the Department of Cardiothoracic surgery of Zhejiang Provincial People's Hospital for their great support and enthusiasm.

\section{Author contribution}

Yihong Xie is responsible for conception and design, acquisition of data and analysis and interpretation of data. Sheliang Shen is responsible for conception and design, acquisition of data and critical revision of the manuscript for important intellectual content. Jun Zhang and Wenyuan Wang are responsible for interpretation of data and drafting the manuscript. Jiayin Zheng is responsible for statistical analysis.

\section{Competing Interests}

The authors have declared that no competing interest exists.

\section{References}

1. Bahrainwala ZS, Grega MA, Hogue CW, et al. Intraoperative hemoglobin levels and transfusion independently predict stroke after cardiac operations. Ann Thorac Surg. 2011; 91:1113-8.

2. Darby P, Kim N, Hare G, Tsui A, et al. Anemia increases the risk of renal cortical and medullary hypoxia during cardiopulmonary bypass. Perfusion. 2013;28:504-11.

3. Reyes G, Prieto M, Alvarez P, et al. Cell saving systems do not reduce the need of transfusion in low-risk patients undergoing cardiac surgery. Interact Cardiovasc Thorac Surg. 2011; 12:189-93.

4. Scrascia G, Rotunno C, Nanna D, et al. Pump blood processing, salvage and re-transfusion improves hemoglobin levels after coronary artery bypass grafting, but affects coagulative and fibrinolytic systems. Perfusion. 2012; 27:270-7.

5. Ferraris VA, Ferraris SP, Saha SP, Hessel EA 2nd, Haan CK, Royston BD, Bridges CR, Higgins RS, Despotis G, Brown JR, Society of Cardiovascular Anesthesiologists Special Task Force on Blood Transfusion, Spiess BD, Shore-Lesserson L, Stafford-Smith M, Mazer CD, Bennett-Guerrero E, Hill SE, Body S. Perioperative blood transfusion and blood conservation in cardiac surgery: the Society of Thoracic Surgeons and the Society of Cardiovascular Anesthesiologists clinical practice guideline. Ann Thorac Surg. 2007; 83 (5 Suppl):S27-S86.

6. Dunning J, Versteegh M, Fabbri A, et al EACTS Audit and Guidelines Committee. EACTS Audit and Guidelines Committee. Guideline on antiplatelet and anticoagulation management in cardiac surgery. Eur J Cardiothorac Surg. 2008; 34:73-92

7. Djaiani G, Fedorko L, Borger MA, et al. Continuous-flow cell saver reduces cognitive decline in elderly patients after coronary bypass surgery. Circulation. 2007; 116:1888-95.

8. Klein AA, Nashef SA, Sharples L, et al. A randomized controlled trial of cell salvage in routine cardiac surgery. Anesth Analg. 2008; 107:1487-95.

9. Attaran S, Mcllroy D, Fabri BM, et al. Intra-operative cell salvage in routine cardiac surgery is ineffective and not cost-effective and should be reserved for selected cases. Interact Cardiovasc Thorac Surg. 2011; 12:824-6.
10. Hardy JF, Perrault J, Tremblay N, et al. The stratification of cardiac surgical procedures according to use of blood products: a retrospective analysis of 1480 cases. Can J Anaesth. 1991; 38:511-7.

11. Parr KG, Patel MA, Dekker R, et al. Multivariate predictors of blood product use in cardiac surgery. J Cardiothorac Vasc Anesth. 2003; 17:176-81.

12. Weltert L, Nardella S, Rondinelli MB, et al. Reduction of allogeneic red blood cell usage during cardiac surgery by an integrated intra- and postoperative blood salvage strategy: results of a randomized comparison. Transfusion. 2013; 53:790-7

13. Fergusson DA, Hébert PC, Mazer CD, et al; BART Investigators. A comparison of aprotinin and lysine analogues in high-risk cardiac surgery. N Engl J Med. 2008; 358:2319-31.

14. Djaiani G, Fedorko L, Borger MA, et al. Continuous-flow cell saver reduces cognitive decline in elderly patients after coronary bypass surgery. Circulation. 2007; 116:1888-95.

15. Vonk AB, Meesters MI, Garnier RP, et al. Intraoperative cell salvage is associated with reduced postoperative blood loss and transfusion requirements in cardiac surgery: a cohort study. Transfusion. 2013; 53: 2782-9.

16. Shore-Lesserson L, Manspeizer HE, DePerio M, et al. Thromboelastography-guided transfusion algorithm reduces transfusions in complex cardiac surgery. Anesth Analg. 1999; 88:312-9.

17. Ji HW, Ma L, Gao XR, Zhang Y, et al. Application of Thromboelastography in Cardiovascular Surgery. Chin J ECC. 2011; 9:170-2.

18. She-liang Shen, Jia-yin Zheng, Jun Zhang, et al. Comparison of Dexmedetomidine and Propofol for Conscious Sedation in Awake Craniotomy: A Prospective, Double-Blind, Randomized, and Controlled Clinical Trial. Annals of Pharmacotherapy. 2013, 47(11): 1391-1399.

19. Shander A, Hofmann A, Ozawa S, et al. Activity-based costs of blood transfusions in surgical patients at four hospitals. Transfusion. 2010; 50:753-65.

20. Niranjan G, Asimakopoulos G, Karagounis A, et al. Effects of cell saver autologous blood transfusion on blood loss and homologous blood transfusion requirements in patients undergoing cardiac surgery on- versus off-cardiopulmonary bypass: a randomised trial. Eur J Cardiothorac Surg. 2006; 30:271-7.

21. Shih RL, Cherng YG, Chao A, et al. Prediction of bleeding diathesis in patients undergoing cardiopulmonary bypass during cardiac surgery: viscoelastic measures versus routine coagulation test. Acta Anaesthesiol Sin. 1997; 35:133-9.

22. De Somer F. Understanding the delicate balance between bleeding and thrombosis: can we use it to our advantage? J Extra Corpor Technol. 2012; 44:13-5.

23. Serrick CJ, Scholz M, Melo A, et al. Quality of red blood cells using autotransfusion devices: a comparative analysis. J Extra Corpor Technol. 2003; 35:28-34.

24. Waters JH, Dyga RM, Waters JF, et al. The volume of returned red blood cells in a large blood salvage program: where does it all go? Transfusion. 2011; 51:26-32. 